\title{
habilidade Competitiva Relativa do Trigo (Triticum aestivum) EM CoNvivênCIA COM AZEvÉm (Lolium multiflorum) OU NABO (Raphanus raphanistrum) ${ }^{1}$
}

\author{
Relative Competitive Ability of Wheat (Triticum aestivum) Intercropped with Italian Ryegrass \\ (Lolium multiflorum) or Wild Radish (Raphanus raphanistrum)
}

RIGOLI, R.P. ${ }^{2}$, AGOSTINETTO, D. ${ }^{3}$, SCHAEDLER, C.E. ${ }^{4}$, DAL MAGRO, T. ${ }^{5}$ e TIRONI, S. ${ }^{6}$

\begin{abstract}
RESUMO - Experimentos em série de substituição possibilitam o estudo da competição inter e intra-específica. A premissa desses experimentos é de que as produtividades das misturas podem ser determinadas pela comparação com a produtividade da monocultura. $\mathrm{O}$ objetivo deste trabalho foi investigar a habilidade competitiva relativa de cultivar de trigo com as espécies daninhas azevém ou nabo. Foram realizados três experimentos em casa de vegetação na UFPel, no ano de 2006. O delineamento utilizado foi o completamente casualizado, com quatro repetições, sendo os tratamentos arranjados em série de substituição. As proporções de plantas de trigo e dos competidores azevém ou nabo foram: $100 / 0,75 / 25,50 / 50,25 / 75$ e 0/100, com população total de 900 plantas $\mathrm{m}^{-2}$. A análise estatística da competitividade foi realizada através de diagramas aplicados aos experimentos substitutivos e interpretações dos índices de competitividade. As relações competitivas entre plantas de trigo e azevém ou entre trigo e nabo são alteradas pela proporção de plantas que compõem a associação; a cultura do trigo apresenta habilidade competitiva superior à do azevém, mas inferior à do nabo, quando as espécies ocorrem em proporções iguais de plantas nas associações, e essas espécies ocupam o mesmo nicho ecológico.
\end{abstract}

Palavras-chave: competição, interferência mútua, série de substituição.

\begin{abstract}
Replacement series experiments make possible the study of inter and intraspecific competition, based on the fact that the yield of the species under competition can be determined by comparing with plants in monoculture. The objective of this work was to investigate the relative competitive ability of wheat crop with the weeds Italian ryegrass or wild radish. Three experiments were conducted under greenhouse at UFPel, in 2006. The treatments were conducted in a completely randomized design, with four replications, with the treatments arranged in replacement series. The proportions of wheat plants and competitors Italian ryegrass or wild radish were: 100/0, 75/ 25, 50/50, 25/75 and 0/100, always with a total population of 900 plants $\mathrm{m}^{-2}$. Competitiveness statistical analysis consisted in applying diagrams to the replacement series and interpreting the competitiveness indices. The competitive relationships between wheat and ryegrass or between wheat and wild radish plants are altered by the proportion of plants that compose the association. Wheat shows superior competitive ability to ryegrass but inferior to wild radish when the species have similar proportions of plants in the associations and when these species occur in the same ecological niche.
\end{abstract}

Keywords: competition, mutual interference, replacement series.

Recebido para publicação em 5.7.2007 e na forma revisada em 4.1.2008.

2 Bióloga, aluna do programa de Pós-Graduação em Fitossanidade da Universidade Federal de Pelotas - UFPel, Caixa Postal 354, 96010-900, Pelotas-RS, <rubiapiesanti@yahoo.com.br>, ${ }^{3}$ Engo-Agro ${ }^{\circ}$, Dr., Prof. da Faculdade de Agronomia da UFPel, Bolsista do CNPq, ${ }^{4}$ Engo-Agr ${ }^{0}$, aluno do programa de Pós-Graduação em Fitossanidade da UFPel, ${ }^{5}$ Eng ${ }^{\text {a }}$-Agr ${ }^{\mathbf{a}}$, Mestre, aluna do Programa de Pós-Graduação em Fitossanidade da UFPel, ${ }^{6}$ Aluno do curso de graduação em Agronomia da UFPel, Bolsista do PET.

Planta Daninha, Viçosa-MG, v. 26, n. 1, p. 93-100, 2008 


\section{INTRODUÇÃO}

A competição entre plantas ocorre quando um (ou mais) dos recursos essenciais ao seu desenvolvimento e crescimento encontra-se em quantidade limitada para atender às necessidades de todos os indivíduos presentes no meio. No ambiente, pode ocorrer competição intra-específica e/ou interespecífica, podendo a última ser mais representativa, dependendo do nicho ecológico.

As plantas daninhas, por apresentarem ocorrência espontânea, possuem variabilidade genética que lhes garante maior adaptação ao ambiente do que espécies cultivadas selecionadas pelo homem. Também, ocorrem variações na proporção entre as populações de plantas da cultura e de espécies daninhas. Nos estudos de competição, é importante estimar não apenas a influência das populações no processo competitivo, mas também da variação nas proporções entre as espécies (Passini, 2001).

Para determinar as interações competitivas entre plantas daninhas e culturas, têm sido desenvolvidas vários métodos, os quais consideram os fatores população, proporção de espécies e arranjo espacial (Radosevich, 1987) e abrangem quatro tipos gerais de experimento: aditivo, sistemático, superficie de resposta e série substitutiva. Em cada método experimental, a resposta de uma espécie é utilizada para descrever a influência da outra na associação por meio de variáveis como produtividade, taxa de germinação, mortalidade de plantas, entre outras.

Os experimentos em série de substituição possibilitam o estudo da competição inter e intra-específica. A premissa desse tipo de experimento é de que as produtividades das associações possam ser determinadas em comparação às do monocultivo. A série de substituição inclui a cultura sozinha e em mistura com plantas daninhas, em que a proporção das duas espécies estudadas varia. A população total de plantas é constante em todos os tratamentos do experimento. Esses experimentos visam indicar qual genótipo ou espécie é mais competitivo (Cousens, 1991).

Várias interpretações para as respostas de produtividade em função da proporção de plantas podem ser consideradas, como: as espécies situam-se tão separadas que não ocorre nenhuma interação entre elas; cada espécie contribui para a produtividade total em proporção direta à sua presença na mistura; duas espécies exercem demandas similares no ambiente, mas diferem em suas respostas, sendo o caso em que uma espécie é mais agressiva que outra e contribui mais que o esperado para a produtividade total; nenhuma das espécies contribui com sua parte esperada para a produtividade total; e a produtividade de duas espécies em qualquer mistura é maior que a obtida no monocultivo, ocorrendo simbiose, mesmo que seja em proporções distintas (Radosevich et al., 1997).

Quando culturas são semeadas em associação com plantas daninhas, com variação na proporção de plantas, elas apresentam vantagem na produtividade relativa, demonstrando que a competição intra-específica normalmente excede a competição interespecífica. (Woldeamlak et al., 2001).

Experimentos substitutivos demonstram que a cultura geralmente é mais competitiva do que a espécie daninha, sob níveis adequados de recursos, porque o efeito das infestantes não se deve somente à maior habilidade competitiva individual delas, mas ao seu grau de infestação (Vilà et al., 2004). Nas áreas agrícolas, as plantas daninhas ocorrem, em geral, em populações superiores às das plantas cultivadas, sendo, freqüentemente, rotuladas como mais competitivas na apreensão e utilização dos recursos. Contudo, deve-se considerar que a população com que as plantas daninhas ocorrem nas lavouras encobre a sua real habilidade em competir, inferindo-se que elas apresentam maior habilidade competitiva, quando, na realidade, o efeito decorre da maior população de plantas (Bianchi et al., 2006).

O conhecimento da habilidade competitiva da cultura do trigo em relação às plantas daninhas, utilizando-se experimentos substitutivos, permite determinar a influência da população de plantas e da proporção de espécies e compreender as interações competitivas, tornando possivel o desenvolvimento de práticas mais eficientes de manejo das plantas daninhas.

A hipótese desta pesquisa foi de que as plantas daninhas, embora possuam maior 
adaptação ao meio do que as espécies cultivadas, apresentam menor habilidade competitiva quando ocorrem em proporções iguais às do trigo sob niveis adequados de recursos. Desse modo, o objetivo da pesquisa foi investigar a habilidade competitiva relativa de cultivar de trigo com as espécies daninhas azevém ou nabo, utilizando-se o método de série de substituição.

\section{MATERIAL E MÉTODOS}

Foram conduzidos três experimentos em casa de vegetação pertencente à Faculdade de Agronomia Eliseu Maciel, da Universidade Federal de Pelotas, no município de Capão do Leão-RS.

O primeiro experimento, com monocultivos de trigo, azevém e nabo, objetivou determinar a população de plantas $\mathrm{m}^{-2}$ a partir da qual a matéria seca da parte aérea (MSPA) por unidade de área $\left(\mathrm{g} \mathrm{m}^{-2}\right)$ torna-se independente da população, de acordo com a "lei de produção final constante" (Radosevich et al., 1997). As populações testadas foram de $1,2,4,8,16,32$, 64 e 128 plantas por vaso (equivalentes a 37 , $74,148,296,592,1.184,2.368,4.736$ plan$\operatorname{tas} \mathrm{m}^{-2}$ ). Esse experimento foi conduzido em delineamento completamente casualizado, com quatro repetições, utilizando-se sementes do cultivar de trigo FUNDACEP 52 e sementes de azevém (Lolium multiflorum) ou nabo (Raphanus raphanistrum). As espécies foram semeadas em vasos com capacidade de 8 litros e diâmetro de $23 \mathrm{~cm}$, preenchidos com Argissolo Vermelho-Amarelo, de textura franco-arenosa, pertencente à unidade de mapeamento Pelotas (Embrapa, 1999). A variável MSPA foi analisada 42 dias após a emergência (DAE). $\mathrm{Na}$ análise dos dados, utilizou-se a produção recíproca para determinar a população de plantas onde a MSPA se tornava constante. Tal população foi de 900 plantas $\mathrm{m}^{-2}$ (dados não apresentados).

$\mathrm{O}$ segundo e terceiro experimentos foram conduzidos em série de substituição, nos meses de setembro e outubro de 2006 , e foram instalados com população de 36 plantas por vaso (900 plantas $\mathrm{m}^{-2}$ ), conforme determinado no primeiro experimento. Os tratamentos foram dispostos em delineamento completamente casualizado, com quatro repetições. Em cada série, as proporções entre plantas de trigo e azevém (experimento 2) e entre trigo e nabo (experimento 3) foram de 100:0 (estande puro do trigo), 75:25, 50:50, 25:75 e 100:0\% (estande puro de azevém ou nabo). As unidades experimentais e o solo utilizado foram idênticos àqueles do experimento 1 . A semeadura foi realizada em densidade superior às populações desejadas em cada tratamento; aos $10 \mathrm{DAE}$, efetuou-se o desbaste para retirada das plantas excedentes.

As variáveis avaliadas aos $42 \mathrm{DAE}$ foram: área foliar (AF); MSPA do trigo, azevém e nabo; estádio de desenvolvimento (ED) do trigo e do azevém; e número de afilhos (NA) para azevém e trigo. A AF foi determinada com auxilio de medidor de área foliar. A MSPA foi quantificada pela pesagem da parte aérea das plantas após serem secas em estufa a $60{ }^{\circ} \mathrm{C}$ por 72 horas. $\mathrm{O}$ ED do trigo e o do azevém foram determinados visualmente pela escala proposta por Haun (1973). Os NA do trigo e do azevém foram determinados por contagem.

Para análise das variáveis MSPA, AF, ED e NA da cultura e dos competidores, utilizouse o método da análise gráfica da produtividade relativa (Radosevich, 1987). Esse procedimento, também chamado de método convencional para experimentos substitutivos, consiste na construção de um diagrama com base na produtividade relativa (PR) e produtividade relativa total (PRT), nas proporções de plantas de $0,25,50,75$ e $100 \%$ do trigo e dos competidores. As produções relativas para cada espécie foram calculadas a partir da produção de cada população e proporção, divididas pela produção média da monocultura naquela população.

Além da PR e da PRT, os resultados obtidos para AF, MSPA das plantas de trigo, azevém e nabo e para ED e NA das plantas de trigo e azevém, expressos em valores médios por planta, foram submetidos à análise de variância. Quando o teste $\mathrm{F}$ indicou significância $(\mathrm{p} \leq 0,05)$, as médias dos tratamentos foram comparadas pelo teste de Dunnett $(\mathrm{p} \leq 0,05)$, considerando-se as respectivas monoculturas como testemunhas.

A produtividade relativa das variáveis avaliadas foi calculada da seguinte forma: $\mathrm{PR}=$ média da mistura/média da monocultura, incluindo-se no cálculo a média por planta de 
cada espécie em cada unidade experimental. A PRT foi representada pela soma das produtividades relativas da cultura e dos competidores nas respectivas proporções de plantas. Caso a PR resultasse em linha reta, considerou-se não haver efeito de uma espécie sobre a outra ou que a habilidade da espécie em interferir sobre a outra era equivalente. Quando a PR resultasse em linha côncava, definiu-se ocorrer prejuízo no crescimento de uma ou de ambas as espécies. Quando a linha apresentada pela PR foi convexa, houve benefício no crescimento de uma ou de ambas as espécies. Quando a PRT foi igual a 1 (linha reta), significou que ocorreu competição pelo(s) mesmo(s) recurso(s); sendo superior a 1 (linha convexa), não ocorreu competição, pelo fato de o suprimento de recursos superar a demanda ou porque as espécies possuiam diferentes demandas pelo(s) recurso(s) do meio; quando inferior a 1 (linha côncava), significou ocorrer antagonismo, havendo prejuizo mútuo ao crescimento de ambas as espécies.

Os indices de competitividade relativa (CR), coeficientes de agrupamento relativo $(\mathrm{K})$ e de agressividade (A) foram calculados na proporção de $50 \%$ de plantas da cultura e dos respectivos competidores. A CR representa o crescimento comparativo da espécie $\mathrm{T}$ (trigo) em relação à $\mathrm{C}$ (competidora); $\mathrm{K}$ indica a dominância relativa de uma espécie sobre a outra; e A aponta qual espécie se manifesta mais competitiva (Cousens, 1991). A interpretação conjunta desses valores indica com maior segurança a competitividade das espécies envolvidas. A espécie $\mathrm{T}$ é mais competitiva que $\mathrm{C}$ quando $\mathrm{CR}>1, \mathrm{Kt}>\mathrm{Kc}$ e $\mathrm{A}>0$. A espécie $\mathrm{C}$ é mais competitiva que T quando $\mathrm{CR}<1, \mathrm{Kt}<\mathrm{Kc}$ e $\mathrm{A}<$ 0 (Hoffman \& Buhler, 2002). Os cálculos foram realizados por meio das seguintes equações, propostas por Cousens \& O’Neill (1993):

$$
\begin{aligned}
& \mathrm{CR}=\mathrm{PR}_{\mathrm{t}} / \mathrm{PR}_{\mathrm{c}} \\
& \mathrm{K}_{\mathrm{t}}=\mathrm{PR}_{\mathrm{t}} /\left(1-\mathrm{PR}_{\mathrm{t}}\right) \\
& \mathrm{K}_{\mathrm{c}}=\mathrm{PR}_{\mathrm{c}} /\left(1-\mathrm{PR}_{\mathrm{c}}\right) \\
& \mathrm{A}=\mathrm{PR}_{\mathrm{t}}-\mathrm{PR}_{\mathrm{c}}
\end{aligned}
$$

Para analisar estatisticamente a produtividade relativa, primeiro foram calculadas as diferenças para os valores de PR obtidos nas proporções de 25, 50 e $75 \%$ de plantas em relação aos valores pertencentes às retas hipotéticas obtidas nas respectivas proporções (Passini, 2001). O teste ' $t$ ', em nivel de 5\% de probabilidade, foi utilizado para testar as diferenças nos índices estudados em relação à reta hipotética (Passini, 2001; Hoffman \& Buhler, 2002). As hipóteses de nulidade utilizadas para testar as diferenças de PR e A eram de que fossem iguais a zero $\left(\mathrm{H}_{\mathrm{O}}=0\right)$; para PRT e $\mathrm{CR}$, as médias seriam iguais a $1\left(\mathrm{H}_{0}=1\right)$; e para o indice $\mathrm{K}$, de que as médias das diferenças entre $\mathrm{K}_{\mathrm{t}}$ e $\mathrm{K}_{\mathrm{c}}$ fossem iguais a zero $\left[\mathrm{H}_{\mathrm{o}}=\left(\mathrm{K}_{\mathrm{t}}-\mathrm{K}_{\mathrm{c}}\right)=0\right]$.

\section{RESULTADOS E DISCUSSÃO}

A análise gráfica dos resultados obtidos para $\mathrm{PR}$ referente às variáveis AF e MSPA demonstrou que o trigo foi mais competitivo que o azevém, sendo a PR do trigo representada por linha convexa e a do azevém por linha côncava (Figura 1). Nesse caso, verificou-se beneficio para a cultura e prejuízo para o competidor. A competição entre as duas espécies ocorreu pelo(s) mesmo(s) recurso(s) do meio, sendo este(s) utilizado(s) mais eficientemente pela cultura. Os desvios de PR da cultura, para as variáveis $\mathrm{AF}$ e MSPA, foram significativos nas proporções de plantas de 50:50 e 25:75, comparados com as respectivas retas hipotéticas. Para a PR do azevém, em ambas as variáveis, todas as proporções apresentaram diferenças significativas (Tabela 1).

As PRT para as variáveis AF e MSPA não apresentaram diferenças significativas, à exceção da $\mathrm{AF}$ na proporção de 25:75 de trigo e azevém. Para ambas as variáveis, em geral, a PRT foi inferior a 1, o que demonstra que houve prejuízo mútuo ao crescimento, ou seja, a competição entre as duas espécies ocorreu pelos mesmos recursos (Tabela 1).

Quanto às variáveis ED e NA do trigo e do azevém, observaram-se valores de PR similares àqueles de AF e MSPA, sendo a cultura mais agressiva que o competidor (Figura 2). Os valores para ED foram significativos somente para o azevém, em todas as proporções de plantas, e para trigo na proporção predominante do competidor (25:75) (Tabela 1). Para NA, somente se verificaram diferenças nas menores proporções de azevém (75:25) e trigo (25:75).

Os desvios de PRT foram inferiores e superiores a 1, em relação às retas hipotéticas para ED e NA, respectivamente. Assim, para ED 

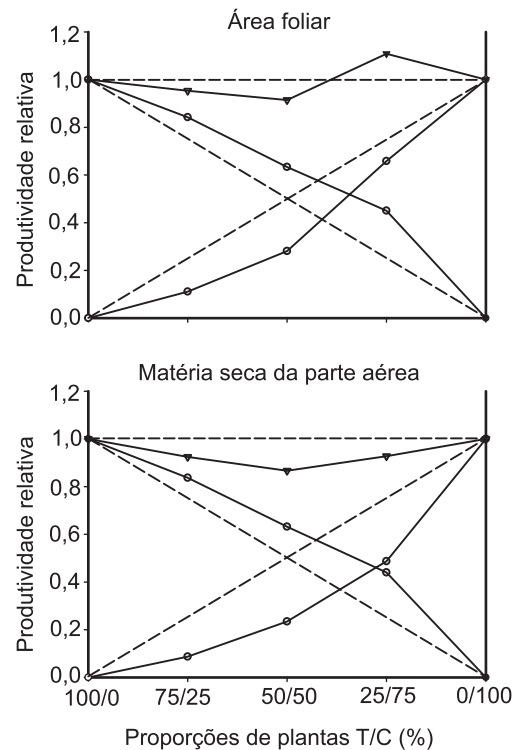

Figura 1 - Produtividade relativa (PR) e total (PRT) para área foliar (AF) e matéria seca da parte aérea (MSPA) do trigo e do azevém (competidor). FAEM/UFPel, Capão do LeãoRS. Círculos cheio $(\bullet)$ e vazio (o) representam a PR da AF e MSPA do trigo (T) e do azevém (C), respectivamente, e ( $\nabla$ ) indica a PRT. As linhas tracejadas referem-se às produtividades relativas hipotéticas, quando não ocorre interferência de uma espécie sobre a outra. ocorreu antagonismo entre as espécies em convivência, enquanto para NA ocorreu sinergismo (Figura 2). Por sua vez, a PRT foi significativa para ED quando houve variação nas proporções da cultura e da planta daninha, enquanto para NA não se verificou diferença (Tabela 2). Quando os valores de PRT são inferiores a 1 , correspondendo a uma linha côncava, ocorre prejuízo mútuo ao crescimento das espécies associadas, e valores superiores a 1 , representados por uma linha convexa, indicam que a competição é evitada, pelo fato de o suprimento de recursos superar a demanda ou porque as espécies possuem diferentes demandas pelos recursos do ambiente.

O crescimento relativo do trigo, indicado pelo índice $C R$, foi superior ao do azevém, havendo dominância da cultura sobre o competidor, conforme indicado pelos indices $\mathrm{K}$ e A (Tabela 2). Estudo demonstrou que, geralmente, a cultura é mais competitiva do que a espécie daninha, porque o efeito das infestantes não se deve somente à sua maior habilidade competitiva individual, mas, principalmente, à população total de plantas (Vilà et al., 2004).

Tabela 1 - Diferenças relativas de produtividade (DPR) para as variáveis área foliar, matéria seca da parte aérea, estádio de desenvolvimento e número de afilhos; e produtividade relativa total (PRT), nas proporções de 75:25, 50:50 e 25:75, de plantas de trigo associadas com azevém e nabo. FAEM/UFPel, Capão do Leão-RS, 2006

\begin{tabular}{|l|c|c|c|}
\hline \multirow{2}{*}{} & \multicolumn{3}{|c|}{ Proporção de planta (trigo:competidor) } \\
\cline { 2 - 4 } & $75: 25$ & $50: 50$ & $25: 75$ \\
\hline Área Foliar & & & $0,20( \pm 0,01)^{*}$ \\
\hline Trigo & $0,09( \pm 0,05)^{\mathrm{ns}}$ & $0,13( \pm 0,04)^{*}$ & $-0,09( \pm 0,02)^{*}$ \\
\hline Azevém & $-0,14( \pm 0,01)^{*}$ & $-0,22( \pm 0,02)^{*}$ & $1,11( \pm 0,02)^{*}$ \\
\hline Total & $0,95( \pm 0,06)^{\mathrm{ns}}$ & $0,91( \pm 0,06)^{\mathrm{ns}}$ & $-0,04( \pm 0,01)^{*}$ \\
\hline Trigo & $-0,27( \pm 0,05)^{*}$ & $-0,14( \pm 0,06)^{*}$ & $0,20( \pm 0,05)^{*}$ \\
\hline Nabo & $0,28( \pm 0,11)^{\mathrm{ns}}$ & $0,10( \pm 0,02)^{*}$ & $1,16( \pm 0,06)^{*}$ \\
\hline Total & $1,01( \pm 0,10)^{\mathrm{ns}}$ & $0,96( \pm 0,04)^{\mathrm{ns}}$ & $0,19( \pm 0,02)^{*}$ \\
\hline Matéria seca da parte aérea & & & $-0,26( \pm 0,04)^{*}$ \\
\hline Trigo & $0,09( \pm 0,04)^{\mathrm{ns}}$ & $0,08( \pm 0,04)^{*}$ & $0,93( \pm 0,05)^{\mathrm{ns}}$ \\
\hline Azevém & $-0,16( \pm 0,01)^{*}$ & $-0,27( \pm 0,02)^{*}$ & $-0,11( \pm 0,01)^{*}$ \\
\hline Total & $0,92( \pm 0,05)^{\mathrm{ns}}$ & $0,87( \pm 0,06)^{\mathrm{ns}}$ & $0,11( \pm 0,03)^{*}$ \\
\hline Trigo & $-0,39( \pm 0,03)^{*}$ & $-0,24( \pm 0,02)^{*}$ & $1,00( \pm 0,02)^{\mathrm{ns}}$ \\
\hline Nabo & $0,33( \pm 0,07)^{*}$ & $0,10( \pm 0,03)^{*}$ & \\
\hline Total & $0,94( \pm 0,06)^{\mathrm{ns}}$ & $0,86( \pm 0,02)^{\mathrm{ns}}$ & $-0,02( \pm 0,01)^{*}$ \\
\hline Estádio de desenvolvimento & & & $-0,05( \pm 0,01)^{*}$ \\
\hline Trigo & $-0,01( \pm 0,01)^{\mathrm{ns}}$ & $-0,01( \pm 0,01)^{\mathrm{ns}}$ & $0,94( \pm 0,01)^{*}$ \\
\hline Azevém & $-0,04( \pm 0,01)^{*}$ & $-0,06( \pm 0,01)^{*}$ & \\
\hline Total & $0,95( \pm 0,01)^{*}$ & $0,93( \pm 0,02)^{\mathrm{ns}}$ & \\
\hline Número de afilhos & & & $0,17( \pm 0,04)^{*}$ \\
\hline Trigo & & $0,15( \pm 0,07)^{\mathrm{ns}}$ & $-0,04( \pm 0,04)^{\mathrm{ns}}$ \\
\hline Azevém & $0,08( \pm 0,16)^{\mathrm{ns}}$ & $-0,08( \pm 0,03)^{\mathrm{ns}}$ & $1,13( \pm 0,07)^{\mathrm{ns}}$ \\
\hline Total & $-0,06( \pm 0,02)^{*}$ & $1,07( \pm 0,09)^{\mathrm{ns}}$ & \\
\hline
\end{tabular}

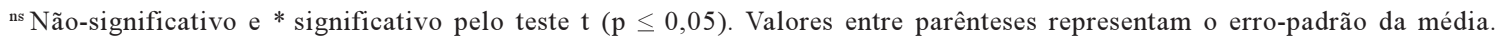



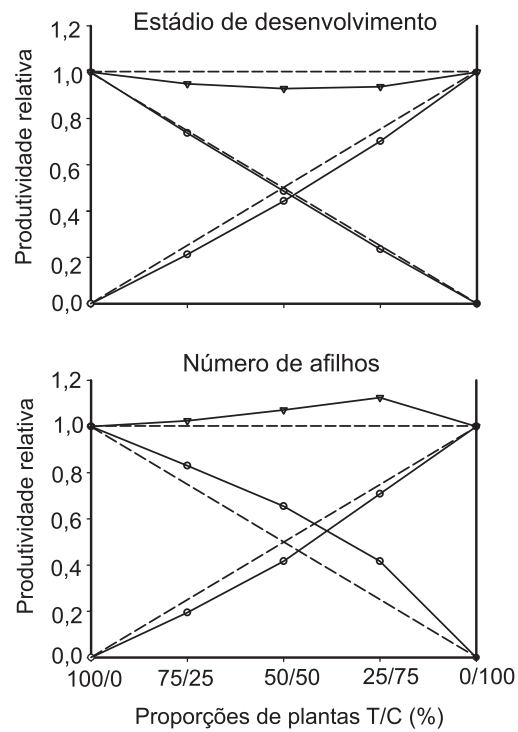

Figura 2 - Produtividade relativa (PR) e total (PRT) para estádio de desenvolvimento (ED) e número de afilhos (NA) do trigo e do azevém (competidor). FAEM/UFPel, Capão do Leão-RS. Círculos cheio $(\bullet)$ e vazio ( $($ ) representam a PR do ED e NA do trigo (T) e do azevém (C), respectivamente, e ( $\mathbf{v})$ indica a PRT. As linhas tracejadas referem-se às produtividades relativas hipotéticas, quando não ocorre interferência de uma espécie sobre a outra.

Entretanto, nem sempre na competição entre espécies da mesma familia ou entre indivíduos da mesma espécie a vantagem é da cultura, principalmente quando algum recurso (água, luz, etc.) é escasso. O arroz-vermelho, embora pertencente à mesma espécie, apresenta superioridade na competição com arroz cultivado (Pantone \& Baker, 1991). Diferença na capacidade competitiva existe entre cultivares de arroz na presença de arroz-vermelho; a característica comum aos biótipos de arroz-vermelho foi a alta capacidade de afilhamento (Estorninos Jr. et al., 2002).

O nabo foi mais competitivo que o trigo para as variáveis AF e MSPA, sendo a PR representada por uma linha côncava, indicando que existe prejuízo no crescimento da cultura (experimento 3) (Figura 3). Desvios das retas observadas, em relação às hipotéticas, foram significativos para ambas as espécies e variáveis, à exceção da proporção da cultura (75:25) para a variável AF (Tabela 1). A PR do competidor foi representada por uma linha convexa, o que revela benefício dessa espécie na associação.

Quanto aos valores de PRT, em geral, não houve diferenças significativas, indicando que as espécies competiram pelo(s) mesmo(s) recurso(s) (PRT igual a 1) (Tabela 1).

Não se observou diferença significativa para o índice $C R$, demonstrando que não houve crescimento superior de uma espécie em relação à outra (Tabela 2). No entanto, constatou-se dominância do nabo sobre o trigo, comprovada pela significância dos índices $\mathrm{K}$ e A (Tabela 2). Resultados semelhantes foram observados para a cultura da soja, em que as proporções da cultura e do nabo alteraram as relações de competição entre as espécies; o nabo exerceu maior competição do que a soja (Bianchi et al., 2006).

Considerando as variáveis AF e MSPA, constatou-se que a competição interespecífica para o componente trigo e a intra-específica para o componente azevém foram as mais expressivas (experimento 2) (Tabela 3). As maiores médias por planta da cultura foram observadas quando esta se apresentava em populações

Tabela 2 - Índices de competitividade entre trigo e competidores (azevém ou nabo), expressos por competitividade relativa (CR) e coeficientes de agrupamento relativo (K) e de agressividade (A). FAEM/UFPel, Capão do Leão-RS, 2006

\begin{tabular}{|c|c|c|c|c|}
\hline & $\mathrm{CR}$ & $\mathrm{K}_{\mathrm{t}=\text { trigo }}$ & $\mathrm{K}_{\mathrm{c}=\text { competidor }}$ & $\mathrm{A}$ \\
\hline \multicolumn{5}{|l|}{ Azevém } \\
\hline $\mathrm{AF}^{1 / 2}$ & $2,27( \pm 0,09)^{*}$ & $1,82( \pm 0,32)$ & $0,39( \pm 0,04)^{*}$ & $0,35( \pm 0,02)^{*}$ \\
\hline $\mathrm{MSPA}^{\underline{2} /}$ & $2,73( \pm 0,17)^{*}$ & $1,83( \pm 0,36)$ & $0,30( \pm 0,03)^{*}$ & $0,40( \pm 0,03)^{*}$ \\
\hline $\mathrm{ED}^{3 /}$ & $1,10( \pm 0,02)^{*}$ & $0,94( \pm 0,04)$ & $0,79( \pm 0,02)^{*}$ & $0,04( \pm 0,01)^{*}$ \\
\hline $\mathrm{NA}^{4 /}$ & $1,56( \pm 0,09)^{*}$ & $2,23( \pm 0,57)$ & $0,72( \pm 0,07)^{*}$ & $0,24( \pm 0,05)^{*}$ \\
\hline \multicolumn{5}{|l|}{ Nabo } \\
\hline$\overline{\mathrm{AF}}$ & $0,60( \pm 0,05)^{\mathrm{ns}}$ & $0,57( \pm 0,78)$ & $1,54( \pm 0,15)^{*}$ & $-0,24( \pm 0,04)^{*}$ \\
\hline MSPA & $0,44( \pm 0,05)^{\mathrm{ns}}$ & $0,35( \pm 0,04)$ & $1,53( \pm 0,17)^{*}$ & $-0,34( \pm 0,04)^{*}$ \\
\hline
\end{tabular}

${ }^{1 /}$ Área foliar; ${ }^{2 /}$ Matéria seca da parte aérea; ${ }^{3 /}$ Estádio de desenvolvimento; ${ }^{4 /}$ Número de afilhos ${ }^{\text {ns }}$ Não-significativo e $*$ Significativo pelo teste $\mathrm{t}(\mathrm{p} \leq 0,05)$. Valores entre parênteses representam os erros-padrão das médias. 

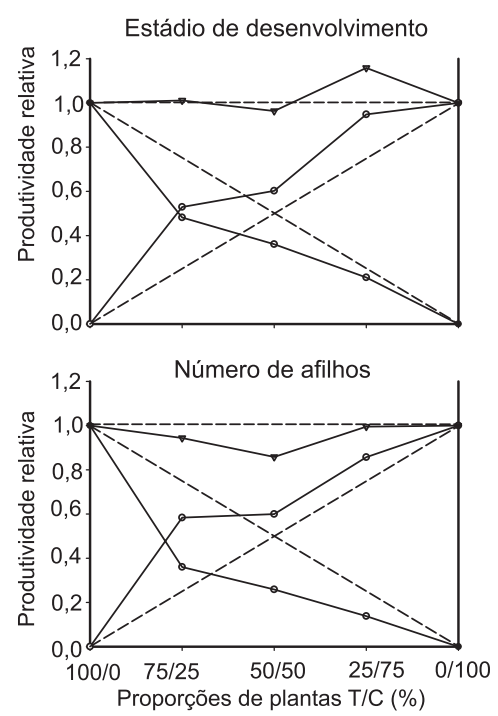

Figura 3 - Produtividade relativa (PR) e total (PRT) para área foliar (AF) e matéria seca da parte aérea (MSPA) do trigo e do nabo (competidor). FAEM/UFPel, Capão do Leão-RS. Círculos cheio (•) e vazio (o) representam a PR da AF e MSPA do trigo (T) e do nabo (C), respectivamente, e ( $\nabla)$ indica a PRT. As linhas tracejadas referem-se às produtividades relativas hipotéticas, quando não ocorre interferência de uma espécie sobre a outra.

menores que a do competidor. Assim, a competição entre trigo e azevém é menos prejudicial que aquela interespecifica para a cultura. Para ED e NA não se verificaram diferenças, à exceção de azevém para a variável $\mathrm{ED}$, o qual foi reduzido com a diminuição de sua população de plantas.
A convivência de trigo com nabo em relação à $\mathrm{AF}$ (experimento 3) demonstrou que a competição intra-específica para o trigo e a interespecífica para o nabo foram as mais vantajosas (Tabela 3). Em relação à MSPA, a cultura apresentou o mesmo comportamento, independentemente da proporção de plantas, enquanto para a planta daninha não se verificou diferença significativa.

Foi relatado que a competitividade da cevada foi relativamente maior que a do trigo para a produtividade total de grãos e matéria seca total (Woldeamlak et al., 2001). A participação de uma planta de cevada na associação competiu em nivel equivalente a oito plantas de trigo. Para a cevada, a presença de uma planta da mesma espécie foi tão prejudicial quanto oito plantas de trigo.

Especulava-se que o trigo e o azevém, por pertencerem à mesma família botânica (Poaceae), competissem pelos mesmos recursos do meio, enquanto o nabo, por pertencer a família distinta (Brassicaceae), ocupasse nicho ecológico distinto. Contudo, os resultados obtidos neste trabalho demonstram que as associações de trigo e azevém e de trigo e nabo ocupam o mesmo nicho, competindo por recurso(s) similar(es) do meio.

Destaca-se, ainda, que os experimentos substitutivos são inadequados para predizer a dinâmica populacional de duas espécies con-

Tabela 3 - Resposta do cultivar de trigo (T) FUNDACEP 52 à interferência do competidor (C) (azevém ou nabo), aos 42 dias após a emergência. FAEM/UFPel, Capão do Leão-RS, 2006

\begin{tabular}{|c|c|c|c|c|c|c|c|}
\hline & \multicolumn{5}{|c|}{ Proporção de planta (T:C) } & \multirow{2}{*}{ CV $(\%)$} & \multirow{2}{*}{ Média } \\
\hline & $100: 0(\mathrm{~T})$ & $75: 25$ & $50: 50$ & $25: 75$ & $0: 100(\mathrm{~T})$ & & \\
\hline \multicolumn{8}{|l|}{ Área foliar } \\
\hline Ensaio 2 - trigo & 43,4 & 48,8 & $55,0^{*}$ & $78,3^{*}$ & - & 8,2 & 56,4 \\
\hline Ensaio 2 - azevém & - & $20,3^{*}$ & $25,8^{*}$ & 40,3 & 45,9 & 11,5 & 33,0 \\
\hline Ensaio 3 - trigo & 18,6 & $11,9^{*}$ & $13,4^{*}$ & 15,6 & - & 17,5 & 14,9 \\
\hline Ensaio 3 - nabo & - & $84,9^{*}$ & 57,9 & 60,8 & 48,1 & 11,8 & 65,9 \\
\hline \multicolumn{8}{|c|}{ Matéria seca da parte aérea } \\
\hline Ensaio 2 - trigo & 0,3 & 0,3 & $0,4^{*}$ & $0,5^{*}$ & - & 9,5 & 0,4 \\
\hline Ensaio 2 - azevém & - & $0,1^{*}$ & $0,1^{*}$ & $0,2^{*}$ & 0,3 & 12,2 & 0,2 \\
\hline Ensaio 3 - trigo & 0,2 & $0,1^{*}$ & $0,1^{*}$ & $0,1^{*}$ & - & 16,8 & 0,2 \\
\hline Ensaio 3 - nabo & - & 1,4 & 0,7 & 0,7 & 0,6 & 19,3 & 1,7 \\
\hline \multicolumn{8}{|c|}{ Estádio de desenvolvimento } \\
\hline Ensaio 2 - trigo & $7,0^{\text {ns }}$ & 6,9 & 6,8 & 6,6 & - & 3,5 & 6,8 \\
\hline Ensaio 2 - azevém & - & $5,9^{*}$ & 6,2 & 6,5 & 7,0 & 6,8 & 6,4 \\
\hline \multicolumn{8}{|l|}{ Número de afilhos } \\
\hline Ensaio 2 - trigo & $2,1^{\mathrm{ns}}$ & 2,4 & 2,7 & 3,5 & - & 7,2 & 2,6 \\
\hline Ensaio 2 - azevém & - & 3,5 & 3,7 & 4,3 & 4,5 & 16,9 & 4,0 \\
\hline
\end{tabular}

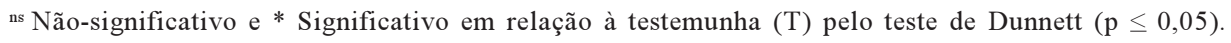


correntes ao longo do tempo, ou seja, não se sabe se ocorrerá redução da população de uma espécie devido a ela ser menos competitiva (Cousens, 1991). Também, considera-se ser um método artificial para implantar em campo, porque a proporção de plantas varia, sendo inapropriado para estudar misturas de espécies com hábitos de crescimento diferentes.

Os resultados dos experimentos mostraram que as relações competitivas entre plantas de trigo e de azevém ou entre trigo e nabo alteram-se em função das proporções de plantas que compõem a associação; a cultura do trigo apresenta habilidade competitiva superior à do azevém, mas inferior à do nabo, quando as espécies ocorrem em proporções iguais de plantas nas associações, e essas espécies ocupam o mesmo nicho ecológico.

\section{LITERATURA CITADA}

BIANCHI, M. A.; FLECK, N. G.; LAMEGO, F. P.

Proporção entre plantas de soja e plantas competidoras e as relações de interferência mútua. Ci. Rural, v. 36, n. 3 , p. 1380-1387, 2006.

COUSENS, R. Aspects of the design and interpretation of competition (interference) experiments. Weed Technol., v. 5 , n. 3, p. 664-673, 1991.

COUSENS, R.; O’NEILL, M. Density dependence of replacement series experiments. Oikos, v. 66, n. 2, p. 347$352,1993$.

EMPRESA BRASILEIRA DE PESQUISA

AGROPECUÁRIA - EMBRAPA. Centro Nacional de Pesquisa de Solos. Sistema brasileiro de classificação de solos. Brasília: 1999. 412 p.

ESTORNINOS JR., L. E.; GEALY, D. R.; TALBERT, R. E. Growth response of rice (Oryza sativa) in a replacement series study. Weed Technol., v. 16, n. 2, p. 401-406, 2002.
HAUN, J. R. Visual quantification of wheat development. Agron. J., v. 65, n. 1, p. 116-119, 1973.

HOFFMAN, M. L.; BUHLER, D. D. Utilizing Sorghum as functional model of crop-weed competition. I. Establishing a competitive hierarchy. Weed Sci., v. 50, n. 4, p. 466-472, 2002 .

KISSMAN, K. G. Plantas infestantes e nocivas. São Paulo: BASF, 1991. p. 67-94.

PANTONE, D. J.; BAKER, J. B. Reciprocal yield analysis of red rice (Oryza sativa) competition in cultivated rice. Weed Sci., v. 39, n. 1, p. 42-47, 1991

PASSINI, T. Competitividade e predição de perdas de rendimento da cultura de feijão quando em convivência com Brachiaria plantaginea (Link) Hitchc. 2001. $130 \mathrm{f}$. Tese (Doutorado em Agronomia) - Escola Superior de Agricultura Luiz de Queiroz, Piracicaba, 2001.

RADOSEVICH, S.; HOLT, J.; GHERSA, C. Weed ecology: implications for vegetation management. 2. ed. New York: Wiley, 1997. 589 p

RADOSEVICH, S. R. Methods to study interactions among crops and weeds. Weed Technol., v. 1, n. 1, p. 190-198, 1987.

SOBKOWICZ, P.; TENDZIAGOLSKA, E. Competition and productivity in mixture of oats and wheat. J. Agron. Crop Sci., v.191, n. 1, p.377-385, 2005.

VILÀ, M.; WILLIAMSON, M.; LONSDALE, M. Competition experiments on alien weeds with crops: lessons for measuring plant invasion impact? Biol. Invasions, v. 6, n. 1, p. 59-69, 2004.

WOLDEAMLAK, A.; BASTIAANS, L.; STRUIK, P. C. Competition and niche differentiation in barley (Hordeum vulgare) and wheat (Triticum aestivum) mixtures under rainfed conditions in the Central Highlands of Eritrea. Neth. J. Agr. Sci., v. 49, n. 5, p. 95-112, 2001. 